Article

\title{
Catalytic Effect of Functional and Fe Composite Biochars on Biofuel and Biochemical Derived from the Pyrolysis of Green Marine Biomass
}

\author{
Omid Norouzi $[$ and Francesco Di Maria *(i) \\ Lar5 Laboratory-Dipertimento di Ingegneria-University of Perugia, via G. Duranti 93, 06125 Perugia, Italy; \\ Omid.norouzisafsari@studenti.unipg.it \\ * Correspondence: Francesco.dimaria@unipg.it; Tel.: +39-075-5853738; Fax: +39-075-5853703
}

Received: 20 September 2018; Accepted: 8 November 2018; Published: 17 November 2018

\begin{abstract}
This study investigated the behavior of two types of modified biochar (functional and iron composite biochars) as a catalyst regarding their surface chemistry and morphological properties and their effects on bio-product derived from pyrolysis of Cladophora glomerata (C. glomerata) macroalagae. Two catalytic pyrolysis experiments were conducted in $25 \mathrm{~mL}$ slow pyrolysis reactor in the presence of biochar-based catalysts at the temperature of $500{ }^{\circ} \mathrm{C}$. For functional biochar, no clear effect on biogas production was observed, whereas iron composite biochar increased the hydrogen content by 7.99 $\mathrm{mml} / \mathrm{g}$ algae. Iron composite biochar with a 3D network structure demonstrated remarkable catalytic behaviors (especially toward hydrogen production) due to its wonderful surface area, high dispersion of iron particles and particular structures and compositions. The biochar derived marine biomass and treatment process developed here could provide a promising path for the low-cost, efficient, renewable and environmental friendly catalysts.
\end{abstract}

Keywords: Cladophora glomerata; pyrolysis; 3D iron oxide composite; functional biochar; biofuel

\section{Introduction}

Char is produced from biomass that is subjected to a thermochemical process (e.g., pyrolysis or hydrothermal gasification) [1,2]. Pre or post-treatment processes change the surface chemistry of biochar, which makes them suitable for different types of application in energy production or storage [3]. For example, Pourhosseini et al. investigated the potential of $\mathrm{HNO}_{3}$ activated biochar as supercapacitor electrodes [4]. In this study, the treated biochar showed improved specific capacitance $376.7 \mathrm{~F} \mathrm{~g}^{-1}$ at the current density of $1 \mathrm{~A} \mathrm{~g}^{-1}$ with an energy density of $42.4 \mathrm{Whkg}^{-1}$. In another study, Salimi et al. applied $\mathrm{HCl}$ treatment biochar as an anode electrode in lithium-ion batteries [5]. The electrochemical results indicated a higher specific discharge capacity $\left(700 \mathrm{mAh} \mathrm{g}^{-1}\right)$ and good cycling stability for HTB at the current density of $0.1 \mathrm{~A} \mathrm{~g}^{-1}$ as compared to the biochar. Generally, in energy storage systems the pores of modified biochars are responsible for the ion exchange in the process and also functional groups enhances the redox-oxidations reactions during the electrochemistry reactions [6]. However, the catalytic mechanisms of biochar materials rely on the surface area [7]. For instance, in our previous studies, it was shown that pyrochar and hydrochar derived from C. glomerata promote the hydrogen-rich gas and phenolic-rich bio-oil production when it served as a catalyst [8,9]. Actually, the existence of numerous pores and presence of alkali and alkaline earth metals all over the surfaces of bio-char can provide surface reaction and some active phases which in turn lead to the further decomposition of complicated structure biomass [10]. Biochar can also offer surfaces that could be dispersed by active phases (e.g., transition or noble metals). Herein Fe has been considered as an active phase and embedded in the 3D structure of the biochar composite because it's better catalytic activity 
toward producing hydrocarbons and the highest hydrogen yield. Jafarian et al. reported the role of different transition metals supported on HMS-ZSM5 and Fe/HMS-ZSM5 catalysts represented much higher effects in reducing the acid functionalities owing to the presence of higher number of acid sites compared to other catalysts [11]

Basically, there are two main treatment techniques for modification of chemical and physical characteristics which are further subdivided into their pertinent treatment (Figure 1). These techniques are intended to significantly alter a characteristic and not two or more characteristics at the same time [12]. The aim of this study was to evaluate the effect of a metal modified biochar and a functional biochar on the pyrolysis of $C$. glomerata, to observe the consequence on bio-products production. The application of metal modified biochar during pyrolysis of biomass is an alternative approach to the catalytic pyrolysis of biomass over conventional catalysts (transition metals supported on alumina, zeolite, silica etc) and this is the first study to be conducted. The main novelties of this study were to:

- Synthesizing functional biochar and a 3D interconnected algal biochar constituting iron nanoparticles

- Investigating the catalytic behavior of functional and iron composite catalysts in pyrolysis of green macroalgae collected from Caspian Sea Coast, Iran

- Comparative study of biochar based catalysts with other conventional catalysts from the valuable chemical production point of view.

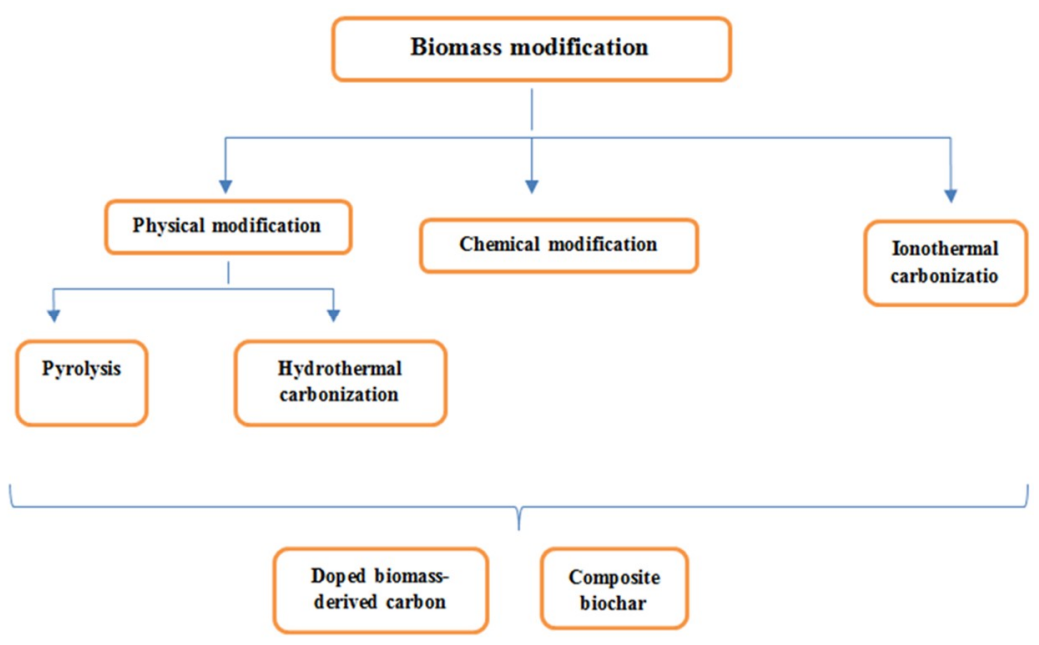

Figure 1. Different types of engineered bio-carbons production.

To the best of our knowledge, no study has been reported the catalytic performance of Fe composite biochar and the main difference between the current composite and other similar works on Fe composite is in association with its specific 3D network structure which makes it appropriate to be used as a catalyst.

\section{Material and Methods}

\subsection{Experimental Setup and Procedure}

A dual bed pyrolysis reactor (lab-scale) was used for catalytic pyrolysis of green macroalgae as a biomass feedstock (Figure 2). The setup consists of an argon capsule connected to a mass flow controller (MFC) using a regulator trough stainless steel connections. The output gas from the MFC enters to the quartz glass tube with a length of $1000 \mathrm{~mm}$ and the internal diameter of $12 \mathrm{~mm}$ that can be heated to the maximum temperature of $900{ }^{\circ} \mathrm{C}$ by the tubular furnace. The output gas from the quartz glass after passing through the reactor bed and clearing the reaction media that is full of oxygen then enters the condenser with produced syngases in the reactions. In the condenser, the condensable 
gases condense to bio-oil and uncondensable gases enter to the columned columns that already filled with the saturated brine sodium chloride. Then, condensed pyrolysis oil was collected and analyzed by GC/MS and syngases (uncondensable gases) in the columned columns were analyzed by gas chromatography after the volume notes [13]. Preparation method of functional and Fe composite biochars is described in the literature [6].

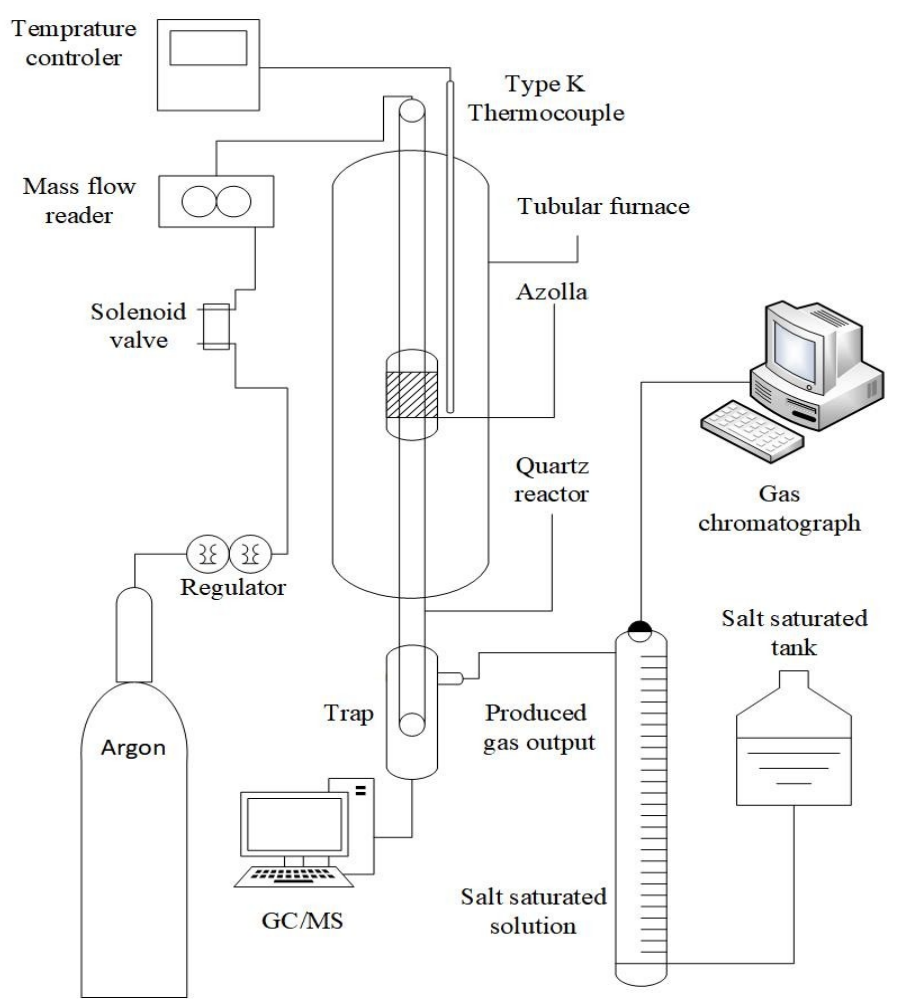

Figure 2. Schematic diagram of the pyrolysis lab-scale setup.

\subsection{Characterization of Biochar-Based Catalysts and Bio-Products}

In order to investigate the surface chemistry and the morphological properties of samples, FT-IR, XRD, Raman and FESEM analyses were using FTIR spectroscopy instruments (Bruker ISS-88), PerkinElmer PHI 6000C ECSA system, Takram P50C0R10 spectrometer and MIRA3 LM Tuscan, respectively. The quality and quantity of produced gaseous mixture were analyzed using gas chromatography technique and Teyfgostar-Compact. Moreover, the bio-oil derived from catalytic pyrolysis was analyzed using gas chromatography/mass spectrometry (GC/MS, Agilent Technology (HP).

\section{Results and Dissuasion}

\subsection{FT-IR Analyses}

FTIR spectra (Figure 3) of both modified biochars exhibits the peaks at 3400, 2927, 1600-1700, $1400-1420,1057,1018$ and $580 \mathrm{~cm}^{-1}$ which are attributed to $\mathrm{O}-\mathrm{H}$ vibrations, asymmetric $\mathrm{C}-\mathrm{H}$ stretching vibration, Carbonyl stretch, $\mathrm{C}-\mathrm{N}$ stretching vibration, $\mathrm{C}-\mathrm{O}-\mathrm{C}$ stretching vibration, $\mathrm{S}=\mathrm{O}$, and $\mathrm{Fe}-\mathrm{O}$. These peaks are commonly are commonly observed in studies on other biochars [14]. However, due to the successful treatment of biochar with iron salts, the Fe-O peak is more intense for a higher ratio of iron. Moreover, functional biochar has an intense peak at $1180 \mathrm{~cm}^{-1}$ which is in association with the acidic functional group caused by the acid reflux with sulfuric acid and nitric acids [15]. These functional groups result in better hydrophilicity characteristics of biochar which in turn lead to the improved water-gas shift reaction during the pyrolysis reaction [16]. 


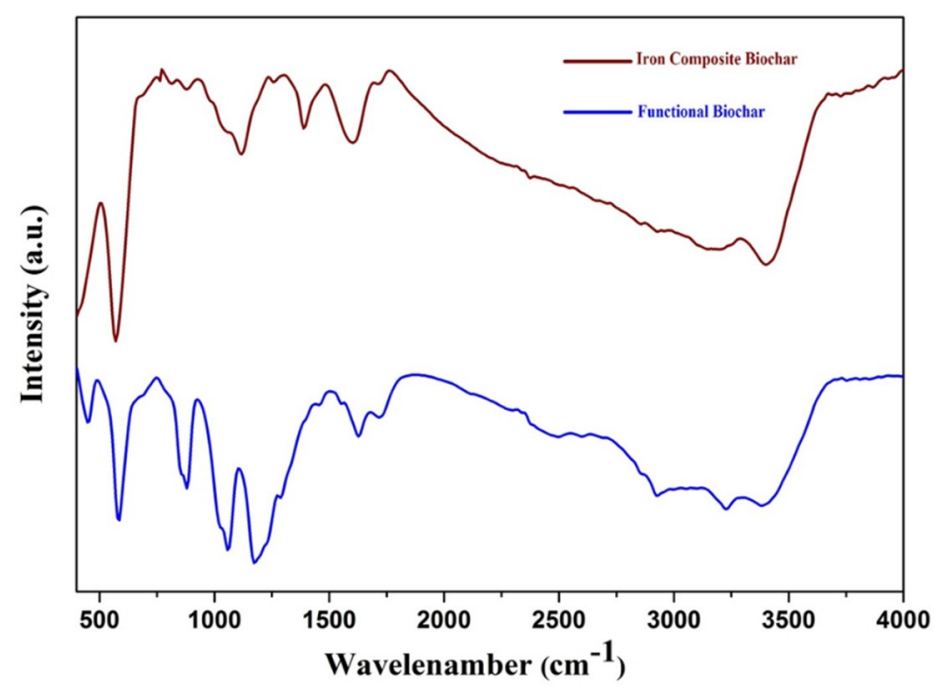

Figure 3. FT-IR analyses of samples.

\subsection{X-ray Diffraction (XRD) Analysis}

Figure 4 shows XRD patterns of biochar-based catalysts. Peaks at 21.1o, 35o, 41.3o, 50.3o, 63.3o, $67.3 \mathrm{o}$, and 74.1o confirm the crystalline structure of $\mathrm{Fe}_{3} \mathrm{O}_{4}$ in the structure of iron composite biochar which is in accordance with Joint Committee on Powder Diffraction Standard (JCPDS) 19-0629 [17,18]. The presence of $\mathrm{Fe}_{3} \mathrm{O}_{4}$ can positively affect the mechanism of biomass pyrolysis. Generally, iron oxide can act as catalysts and results in a higher percentage of hydrocarbons (aromatic and non-aromatic) compared to non- catalytic pyrolysis. According to the results obtained from this study, the most selectivity of hydrocarbon is related to the Fe composite biochar [16].

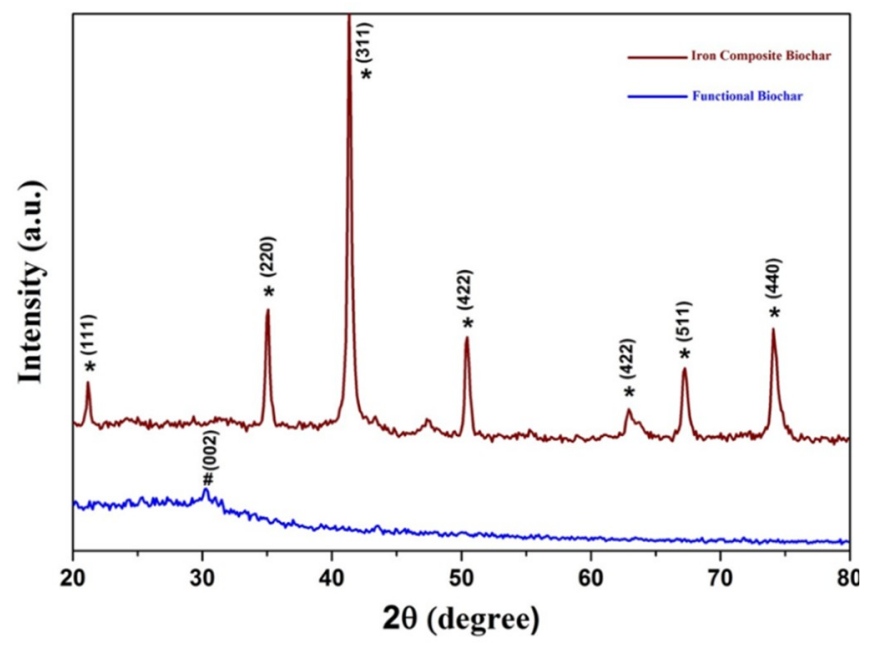

Figure 4. XRD analyses of samples.

\subsection{Raman Spectroscopy Analysis}

In order to compare the disordered degree of both the composite and functional biochars, Raman analyses were performed and the spectra are shown in Figure 5. The peaks around 1345 (D band) and 1570 ( $\mathrm{G}$ band) $\mathrm{cm}^{-1}$ belongs to the turbostratic and graphite-like structures, respectively. The intensity ratio of $\mathrm{D}$ and $\mathrm{G}$ bands for functional and iron composite is 0.96 and 1.29, respectively, which confirm a higher degree in graphite for iron composite than functional biochar $[19,20]$. This phenomenon is due to the better reduction of the biochar by iron particles [19]. Three peaks at 332, 525, and $680 \mathrm{~cm}^{-1}$ in iron composite's spectrum assigns to the vibrational modes of $\mathrm{Eg}$, $\mathrm{T} 2 \mathrm{~g}$, and A1g, respectively. 


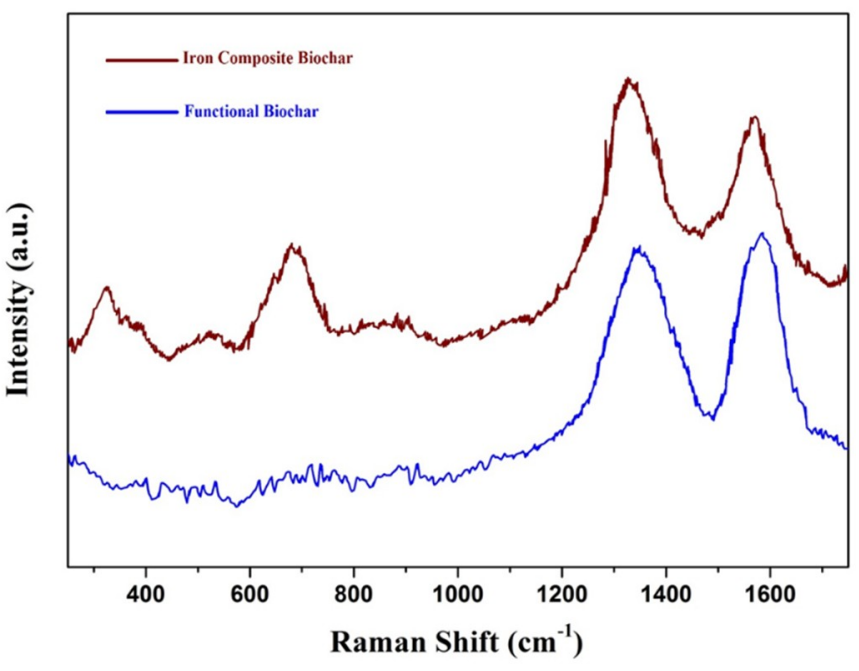

Figure 5. Raman analyses of samples.

\subsection{FESEM Images}

Figure 6 shows the 3D structures of both functional and iron composite biochars. These kinds of structure can act as channels for increasing the density of reactants and hence create a locally higher pressure. We guess that with the assistance of functional groups which are mentioned in FT-IR analyses, during the hydrothermal process, Fe particles were efficiently dispersed over the iron composite biochar surface and caused to two kinds of nano organization structure nanohusk and porous spheres [6].

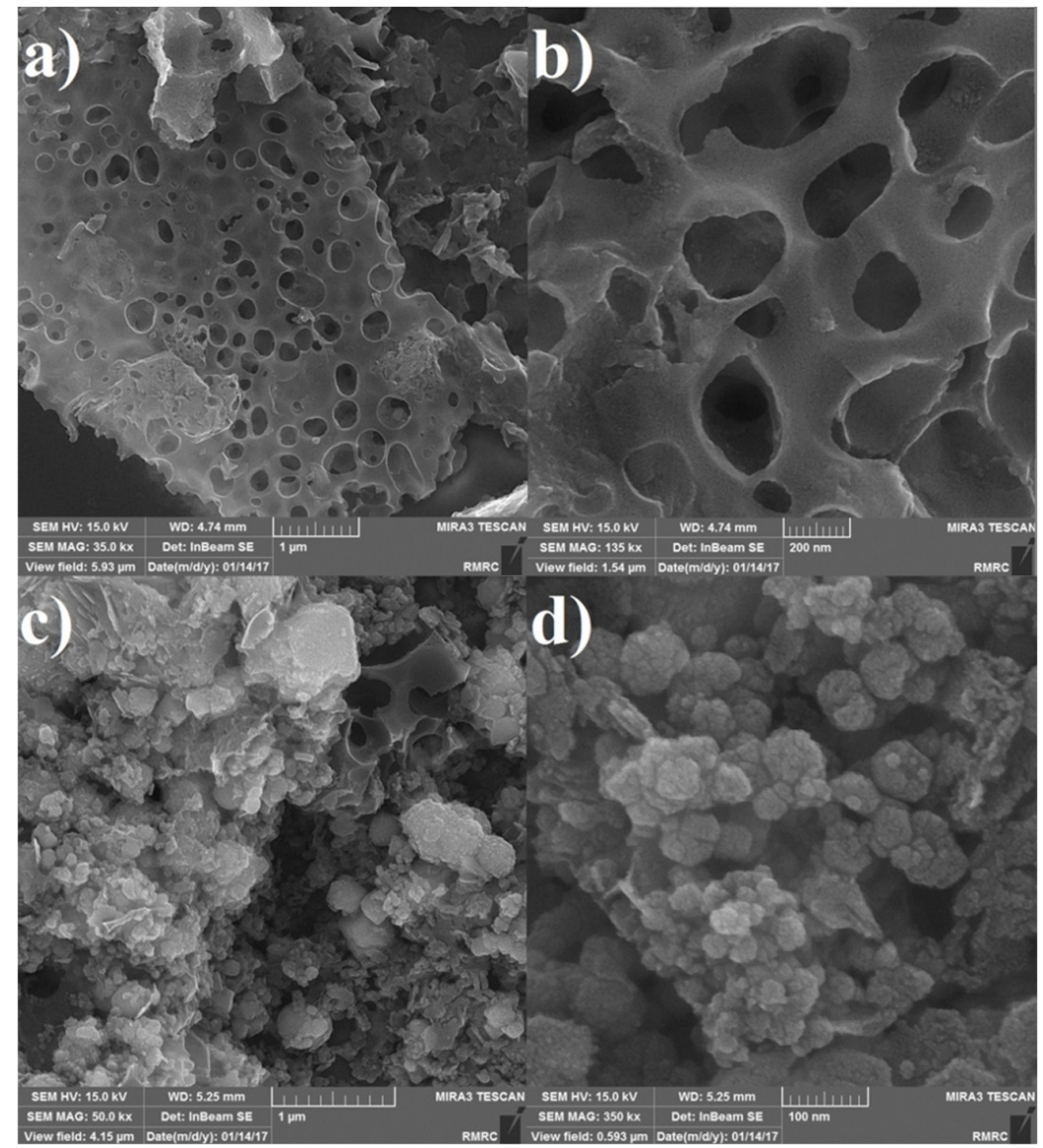

Figure 6. FESEM analyses of functional biochar $(\mathbf{a}, \mathbf{b})$ and Iron composite biochar $(\mathbf{c}, \mathbf{d})$. 


\subsection{Gas Composition Analyses}

The effect of the biochar based catalysts on the composition of pyrolysis products at the temperature of $500{ }^{\circ} \mathrm{C}$ is shown in Figure 7 As seen, the gas, bio-oil and biochar content in the presence of iron composition biochar was 43, 41 and $16 \mathrm{wt} \%$, respectively. This iron composite biochar has a better function as compared to functional biochar and this is due to its higher surface area and presence of iron particles as an active phase, by which water-gas shift reaction has been enhanced [21]. In both catalytic experiments, hydrogen was the most prevalent component $(7.9 \mathrm{mmol} / \mathrm{g} \mathrm{C}$. glomerata for iron composite biochar and $4.3 \mathrm{mmol} / \mathrm{g} \mathrm{C.} \mathrm{glomerata} \mathrm{for} \mathrm{functional} \mathrm{biochar).}$
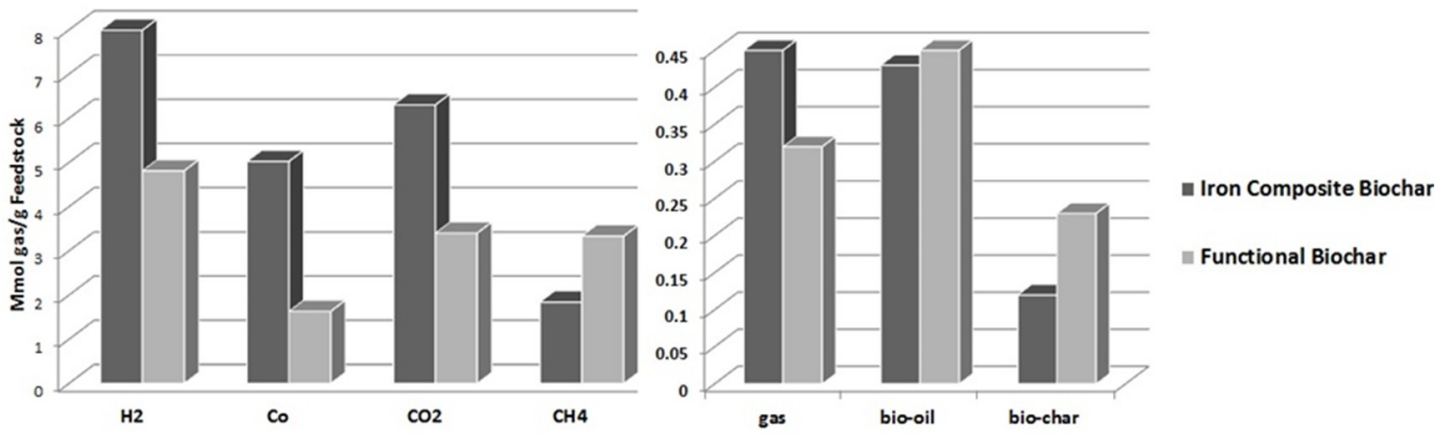

Figure 7. The effect of the biochar based catalysts on the composition of pyrolysis products (The experiments have been carried out in duplicates and the average values are within the standard deviation of $\pm 1.0 \%$ ).

\subsection{Chemical Composition of Bio-Oil}

The composition of bio-oil obtained from the pyrolysis of C. glomerata and its blends with both iron composite biochar and functional biochar as a catalyst is shown in Figure 8 . In this part, chemicals detected by GC/MS categorized in terms of functional groups into acids, phenols, ketones, N-compounds, furans, and alcohols to investigate the selectivity of compounds. As already mentioned (in Section 3.5), iron composite biochar has better catalytic activity than functional biochar. The hydrocarbons portion is the most prevalent chemical in the bio-oil obtained from catalytic pyrolysis of C. glomerata over iron composition biochar (23.4 Area\%). As compared to the non-catalytic test, ketonization reaction is considerable because the selectivity of acids was decreased and the selectivity of ketones was increased during catalytic tests. Moreover, the phenols were increased with the addition of functional biochar (8.5-30\%). Thus, we can reach the conclusion that functional biochar has been enhanced oligomerization reactions to produce olefins and aromatic hydrocarbons. These results were in agreement with our previous studies regarding catalytic pyrolysis of biomass $[8,13]$.

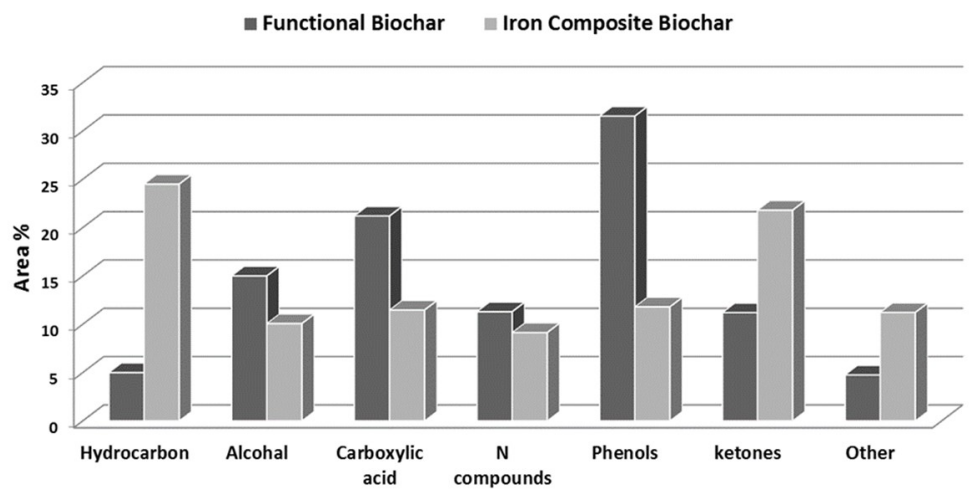

Figure 8. Effect of biochar-based catalysts on the chemical composition of C. glomerata (The experiments have been carried out in duplicates and the average values are within the standard deviation of $\pm 1.0 \%$ ). 


\section{Comparison with Previous Results}

Having just presented the first published results for catalytic pyrolysis of C. glomerata over functional and iron composite biochars as a catalyst via the slow pyrolysis system, we now compare some of these results with previous work on pyrolysis of Cladophora glomerata (green macroalgae) and Gracilaria gracilis (red macroalgae) in the presence of raw biochar, $\mathrm{ZH}$ composites and multi-metal catalyst. As seen in Table 1, bio-oil derived from pyrolysis of C. glomerata over iron composite biochar, an optimal temperature, showed lower corrosive nature than that of obtained from catalytic pyrolysis of green and red macroalage over other catalysts, as it had lower acids content selectivity. Table 1 also shows that the yields of $\mathrm{H} 2$ reported in this research for pyrolysis of $C$. glomerata over iron composite biochar is higher than the yield obtained by pyrolysis of red and green macroalgae over other catalysts. Thus, it appears that iron composite biochar has a significant effect on the production of hydrogen and suppressing the production of acids.

Table 1. Bioproducts from pyrolysis of Caspian Sea Coast marine biomasses at an optimal temperature over five different kinds of catalysts.

\begin{tabular}{cccccc}
\hline Macroalgae Samples & $\begin{array}{c}\text { C. Glomerata } \\
{[8]}\end{array}$ & $\begin{array}{c}\text { G. Gracilis } \\
{[22]}\end{array}$ & $\begin{array}{c}\text { C. Glomerata } \\
{[13]}\end{array}$ & C. Glomerata & C. Glomerata \\
\hline Maximum Yield of Bio-Oil (wt\%) & 39 & 42 & 29 & 43 & 45 \\
\hline Catalyst & Biochar & $\begin{array}{c}\text { ZH-20 } \\
\text { composite }\end{array}$ & $\begin{array}{c}\text { Multi-metal } \\
\text { catalyst }\end{array}$ & $\begin{array}{c}\text { Iron composite } \\
\text { biochar }\end{array}$ & $\begin{array}{c}\text { Functional } \\
\text { biochar }\end{array}$ \\
\hline Acids Selectivity (\%) & 28.55 & 22.45 & 20.12 & 11.47 & 21.20 \\
\hline Phenols Selectivity (\%) & 8.50 & 6.28 & 2.39 & 11.80 & 31.54 \\
\hline $\mathrm{H}_{2}$ Yield (mmol/g Feedstock) & 8.85 & 7.58 & 1.23 & 7.99 & 4.81 \\
\hline $\mathrm{CO}_{2}$ Yield (mmol/g Feedstock) & 11.25 & 11.48 & 2.94 & 6.30 & 3.40 \\
\hline $\mathrm{CO}_{\text {Yield (mmol/g Feedstock) }}$ & 2.82 & 2.97 & 1.25 & 5.02 & 1.63 \\
\hline $\mathrm{CH}_{4}$ Yield (mmol/g Feedstock) & 0.80 & 3.58 & 0.74 & 1.84 & 3.33 \\
\hline
\end{tabular}

\section{Conclusions}

In this study, modified biochars derived from C. glomerata as an abundant harmful algal biomass found in coastal areas worldwide was utilized as a catalyst to upgrade bio-products derived from slow pyrolysis. Iron composition biochar showed an interconnected 3D pore network carbon constituting iron nanoparticles and higher surface area, which can act as an active phase and improve the surface reaction. Iron composition biochar showed good catalytic activity in terms of cracking and promotion of hydrogen-rich gas. This work presents iron composite biochar as a promising catalyst and introduces it a for variety of research and practical applications.

Author Contributions: O.N. convinced the original idea and carried out the experiments and characterizations and F.D.M. supervised the project. O.N. wrote the manuscript with support from F.D.M.

Acknowledgments: The authors are very grateful to the editor for offering the opportunity to publish a paper in Special Issue entitled "Cultivation and Downstream Processing of Microalgal Biomass". In addition, we would like to thank M. Toufiq Reza (Ohio University) for the information and data provided to the study.

Conflicts of Interest: The authors declare no conflict of interest.

\section{References}

1. Thines, K.R.; Abdullah, E.C.; Mubarak, N.M.; Ruthiraan, M. Synthesis of magnetic biochar from agricultural waste biomass to enhancing route for waste water and polymer application: A review. Renew. Sustain. Energy Rev. 2017, 67, 257-276. [CrossRef]

2. Mumme, J.; Srocke, F.; Heeg, K.; Werner, M. Use of biochars in anaerobic digestion. Bioresour. Technol. 2014, 164, 189-197. [CrossRef] [PubMed] 
3. Jung, K.W.; Hwang, M.J.; Jeong, T.U.; Ahn, K.H. A novel approach for preparation of modified-biochar derived from marine macroalgae: Dual purpose electro-modification for improvement of surface area and metal impregnation. Bioresour. Technol. 2015, 191, 342-345. [CrossRef] [PubMed]

4. Pourhosseini, S.E.M.; Norouzi, O.; Naderi, H.R. Study of micro/macro ordered porous carbon with olive-shaped structure derived from Cladophora glomerata macroalgae as efficient working electrodes of supercapacitors. Biomass Bioenergy 2017, 107, 287-298. [CrossRef]

5. Salimi, P.; Javadian, S.; Norouzi, O.; Gharibi, H. Turning an environmental problem into an opportunity: Potential use of biochar derived from a harmful marine biomass named Cladophora glomerata as anode electrode for Li-ion batteries. Environ. Sci. Pollut. Res. 2017, 24, 27974-27984. [CrossRef] [PubMed]

6. Pourhosseini, S.E.M.; Norouzi, O.; Salimi, P.; Naderi, H.R. Synthesis of a Novel Interconnected 3D Pore Network Algal Biochar Constituting Iron Nanoparticles Derived from a Harmful Marine Biomass as High-Performance Asymmetric Supercapacitor Electrodes. ACS Sustain. Chem. Eng. 2018, 6, 4746-4758. [CrossRef]

7. Osman, A.I. Enhanced catalytic activity of Ni on -Al $2 \mathrm{O} 3$ and ZSM-5 on addition of ceria zirconia for the partial oxidation of methane. Appl. Catal. B Environ. 2017, 212, 68-79. [CrossRef]

8. Norouzi, O.; Jafarian, S.; Safari, F.; Tavasoli, A.; Nejati, B. Promotion of hydrogen-rich gas and phenolic-rich bio-oil production from green macroalgae Cladophora glomerata via pyrolysis over its bio-char. Bioresour. Technol. 2016, 219, 643-651. [CrossRef] [PubMed]

9. Safari, F.; Norouzi, O.; Tavasoli, A. Hydrothermal gasification of Cladophora glomerata macroalgae over its hydrochar as a catalyst for hydrogen-rich gas production. Bioresour. Technol. 2016, 222, 232-241. [CrossRef] [PubMed]

10. Safari, F.; Javani, N.; Yumurtaci, Z. Hydrogen production via supercritical water gasification of almond shell over algal and agricultural hydrochars as catalysts. Int. J. Hydrogen Energy 2017, 43, 1-10. [CrossRef]

11. Jafarian, S.; Tavasoli, A. A comparative study on the quality of bioproducts derived from catalytic pyrolysis of green microalgae Spirulina (Arthrospira) plantensis over transition metals supported on HMS-ZSM5 composite. Int. J. Hydrogen Energy 2018, 43, 19902-19917. [CrossRef]

12. Yin, C.Y.; Aroua, M.K.; Daud, W. Review of modifications of activated carbon for enhancing contaminant uptakes from aqueous solutions. Sep. Purif. Technol. 2007, 52, 403-415. [CrossRef]

13. Sabegh, M.Y.; Norouzi, O.; Jafarian, S.; Khosh, A.G.; Tavasoli, A. Pyrolysis of marine biomass to produce bio-oil and its upgrading using a novel multi-metal catalyst prepared from the spent car catalytic converter. Bioresour. Technol. 2018, 249, 473-478. [CrossRef] [PubMed]

14. Nanda, S.; Dalai, A.K.; Gökalp, I.; Kozinski, J.A. Valorization of horse manure through catalytic supercritical water gasification. Waste Manag. 2016, 52, 147-158. [CrossRef] [PubMed]

15. Duan, X.; Wang, D.; Qian, G.; Walmsley, J.C.; Holmen, A.; Chen, D.; Zhou, X.G. Fabrication of K-promoted iron/carbon nanotubes composite catalysts for the Fischer-Tropsch synthesis of lower olefins. J. Energy Chem. 2016, 25, 311-317. [CrossRef]

16. Taghavi, S.; Norouzi, O.; Tavasoli, A.; Di Maria, F.; Signoretto, M.; Menegazzo, F.; Di Michele, A. Catalytic conversion of Venice lagoon brown marine algae for producing hydrogen-rich gas and valuable biochemical using algal biochar and Ni/ SBA-15 catalyst. Int. J. Hydrogen Energy 2018, 43, 19918-19929. [CrossRef]

17. Gao, Y.H.; Niu, H.L.; Chen, Q.W. Preparation and characterization of BaCO3 single-crystalline nanowires by a solvothermal process. Chin J. Inorg. Chem. 2003, 19, 37-40.

18. Liu, W.; Tian, K.; Jiang, H.; Yu, H. Facile synthesis of highly efficient and recyclable magnetic solid acid from biomass waste. Sci. Rep. 2013, 3, 2419. [CrossRef] [PubMed]

19. Ru, H.; Bai, N.; Xiang, K.; Zhou, W.; Chen, H.; Zhao, X.S. Porous carbons derived from microalgae with enhanced electrochemical performance for lithium-ion batteries. Electrochim. Acta 2016, 194, 10-16. [CrossRef]

20. Azargohar, R.; Nanda, S.; Kozinski, J.A.; Dalai, A.K.; Sutarto, R. Effects of temperature on the physicochemical characteristics of fast pyrolysis bio-chars derived from Canadian waste biomass. Fuel 2014, 125, 90-100. [CrossRef] 
21. Jiang, J.; Zhang, L.; Wang, X.; Holm, N.; Rajagopalan, K.; Chen, F.; Ma, S.G. Highly ordered macroporous woody biochar with ultra-high carbon content as supercapacitor electrodes. Electrochim. Acta 2013, 113, 481-489. [CrossRef]

22. Norouzi, O.; Tavasoli, A.; Jafarian, S.; Esmailpour, S. Catalytic upgrading of bio-products derived from pyrolysis of red macroalgae Gracilaria gracilis with a promising novel micro/mesoporous catalyst. Bioresour. Technol. 2017, 243, 1-8. [CrossRef] [PubMed] 